\title{
TCEC11: the 11th top chess engine championship
}

Article

Accepted Version

Haworth, G. and Hernandez, N. (2018) TCEC11: the 11th top chess engine championship. ICGA Journal, 40 (3). pp. 216223. ISSN 1389-6911 doi: https://doi.org/10.3233/ICG-190081 Available at https://centaur.reading.ac.uk/75899/

It is advisable to refer to the publisher's version if you intend to cite from the work. See Guidance on citing.

Published version at: https://doi.org/10.3233//CG-190081

To link to this article DOI: http://dx.doi.org/10.3233/ICG-190081

Publisher: The International Computer Games Association

All outputs in CentAUR are protected by Intellectual Property Rights law, including copyright law. Copyright and IPR is retained by the creators or other copyright holders. Terms and conditions for use of this material are defined in the End User Agreement.

\section{www.reading.ac.uk/centaur}

\section{CentAUR}

Central Archive at the University of Reading

Reading's research outputs online 


\section{TCEC11: the 11 $1^{\text {th }}$ Top Chess Engine Championship}

Guy Haworth and Nelson Hernandez ${ }^{1}$

Reading, UK and Maryland, USA

After the successes of TCEC Season 10 (Haworth and Hernandez, 2018a), the Top Chess Engine Championship moved straight on to Season 11, starting January $3^{\text {rd }} 2018$ but with a new structure. Five divisions, each of eight engines, played one or more 'DRR' double round robin phases each, with promotions and relegations following. Classic tempi gradually lengthened and the Premier division's top two engines played a 100-game match to determine the Grand Champion. This gave TCEC the opportunity to welcome in nine new engines, see Figs. $1 \& 2$, and allowed the strategy for the selection of mandated openings to be finessed from division to division.

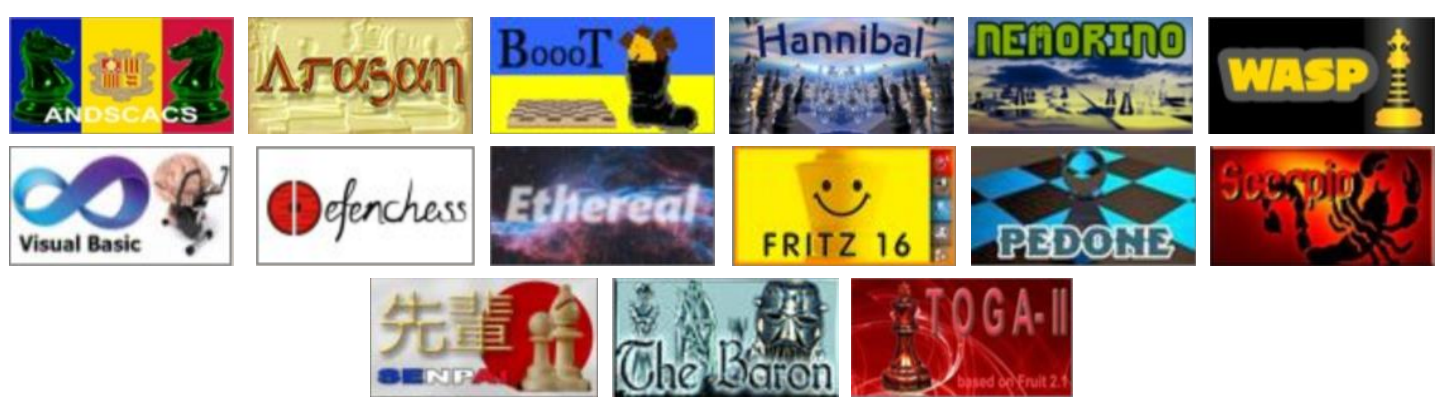

Fig. 1. Logos for six rebadged TCEC10 engines (top row) and for nine engines which were not in TCEC10.

Besides using FIDE's 3x-repetition and 50-move drawing rules, TCEC terminates a game at move 40 or later if both engines had |evaluation $\mid<0.05$ for ten consecutive plies in the current phase, i.e., since the last pawn-advance and/or capture. TCEC adjudicates 5-man endgames using the Gaviota DTM EGTs which do not recognise the 50-move rule. Games which are apparently decisive are terminated by TCEC if both engines consistently agreed for the last eight plies that the evaluation is at least 6.5 or at most -6.5. No cases of fortresses being mistakenly seen as wins have been logged so far.

The common platform server was formidable and identical to that of TCEC10: Windows Server 2012 R2 supporting UCI and Xboard (Winboard) engines. Only ChessbrainVB and Scorpio used the Xboard protocol. Hardware included two Intel ${ }^{\circledR} \mathrm{Xeon}^{\circledR} \mathrm{E} 5-2699 \mathrm{~V} 4$ processors @ $2.8 \mathrm{GHz}$ (Intel, 2017), 64GB of DDR4 ECC RAM and a 240GB Crucial CT250M500 SSD. Engines could use 43 threads throughout, the $44^{\text {th }}$ thread being for the operating system. Multi-threading, Windows Large Pages, Opening Books and pondering were not used. TCEC provided Gaviota, Nalimov, Scorpio and Syzygy 'EGT' endgame tables on the server (Ballicora, 2018; de Man, 2018; Haworth, 2014; Nalimov et al, 2000; Shawul, 2018). The largest ever Knodes/sec and EGT-accesses/move were visible in the GUI.

\footnotetext{
${ }^{1}$ Corresponding author: guy.haworth@bnc.oxon.org
} 


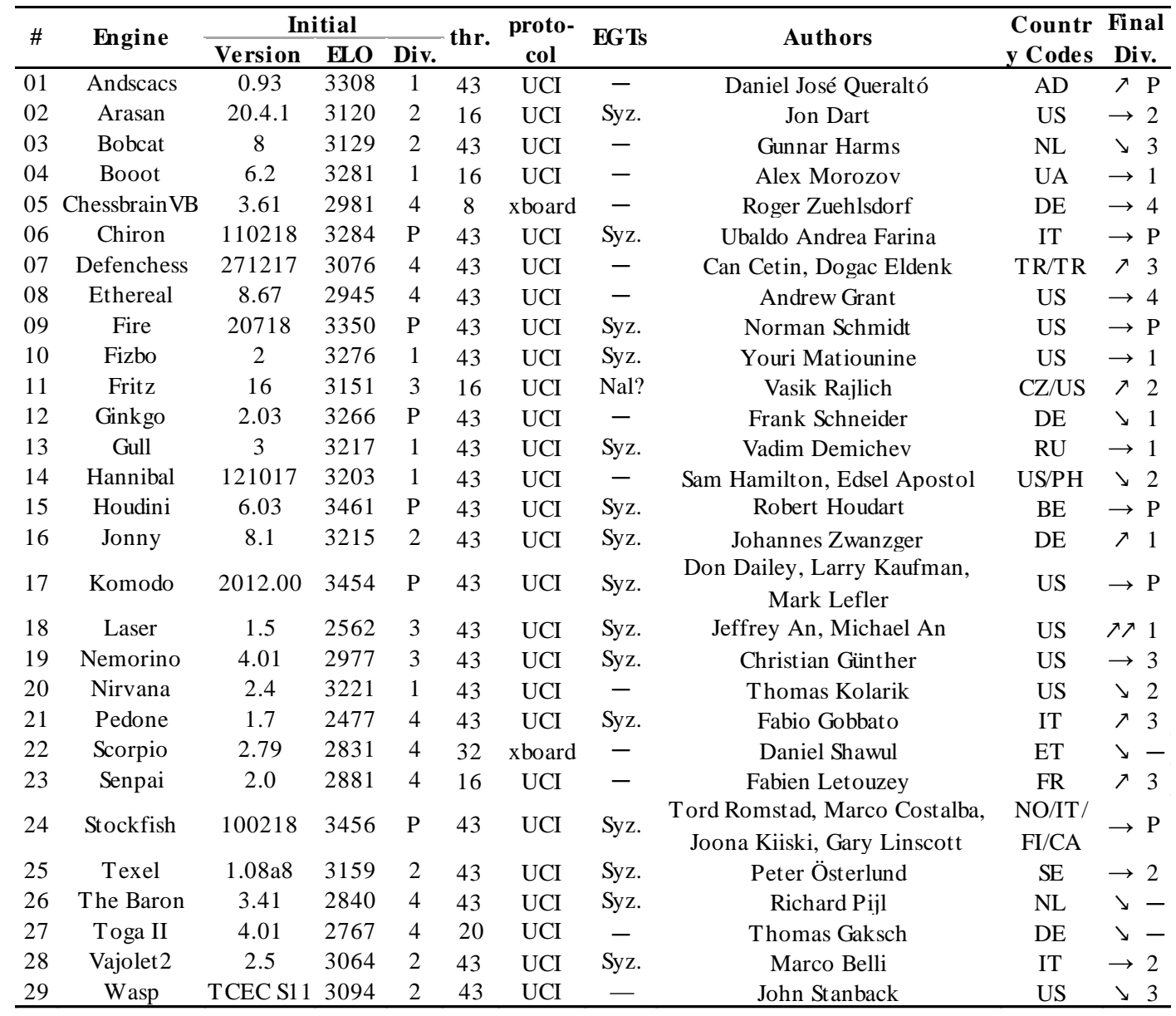

Fig. 2. The TCEC11 engines, details and authors.

\section{Division 4: one DRR phase, 14 rounds, 56 games, tempo $30^{\prime}+10^{\prime \prime} / \mathrm{m}$}

These engines did not take part in TCEC10 and the top five were promoted to play in Division 3.

The selection of openings for TCEC has been made freely by Nelson Hernandez (2018) who has led on this activity since the middle of Season 5 in 2013, sometimes with the help of invited assistants. His approach has varied across the seasons, and now across divisions, as part of the TCEC tournament evolution determined by TCEC chief Anton Mihailov. This is a good moment to say that neither author claims to be a club player but they are enthusiasts for the game, here making contributions based on statistical rather than chessic observation.

Since 2004, Nelson has diligently collected human and engine games from a multitude of sources. These have been filtered to meet criteria including game length, uniqueness, time controls and Elo - and then adjudicated so that game results match the ending or EGT-truncated positions. The resulting 'CATOBASE' contains over 4 billion unique positions and in conjunction with proprietary query tools, permits Nelson to search for positions that match very specific quantitative criteria: frequency, drawrate, success rate, ECO, ply length. In this way, he has successfully kept the TCEC draw-rate well below that of undirected engine contests while providing the desired level of opening variety at the highest 
levels of competition in the later divisions. Here, the seven most common two-move openings in CATOBASE were allocated to rounds 1-7, and to rounds 8-14 with colours reversed, as in Fig. 3.

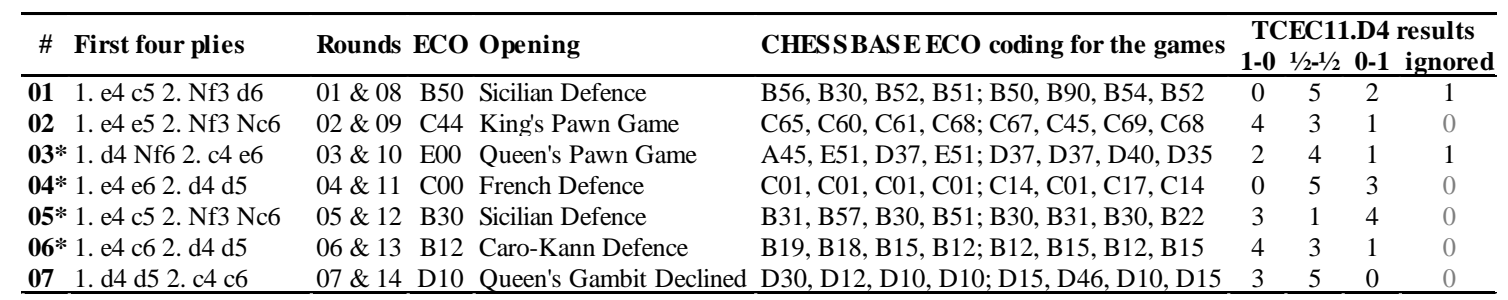

Fig. 3. CATOBASE's most common two-move openings and CHESSBASE's ECO classification of the resulting games.

The cross-tables include a normalised Sonnerborn-Berger score ' $\mathrm{nSB}$ ' $=\mathrm{SB} / \# \mathrm{DRR}{ }^{2}$ in case readers wish to compare SB scores across divisions. All rounds have four games so game $r . n$ is game $4 r-4+n$ in the pgn files (Haworth and Hernandez, 2018b). The colour-flipped pairings of engines are 28 games apart.

With a range of 599 ELO across the participants, Division 4 saw a 53.6\% win-rate, 28.6\% 1-0 and $25.0 \%$ 0-1. The longest win (0-1) was ETHEREAL-TOGA g17 at 145 moves and the longest draw was SENPAI-PEDONE g36 at 146 moves. This had been a theoretical draw for 86 moves and ended in a KQRPk stalemate. Only 16.7\%, 5/30, wins were below the diagonal in the final cross-table of Figure 4, perhaps the most striking being g37, TOGA-SENPAI, and g45, TOGA-ETHEREAL.

\begin{tabular}{|c|c|c|c|c|c|c|c|c|c|c|c|c|c|c|}
\hline \# Engine & ELO & Pts & DRR & SB & nSB & D'chess & Senpai & Pedone & Ethrl & Ch'brain & Toga & T'Baron & Scorpio & Move \\
\hline 1 Defenchess 271217 & 3076 & 10.0 & 1 & 66.25 & 66.25 & & $==$ & $1=$ & $1=$ & 11 & $=1$ & $==$ & $=1$ & $\pi$ \\
\hline 2 Senpai 2.0 & 2881 & 9.0 & 1 & 54.00 & 54.00 & $==$ & & $==$ & $==$ & $==$ & 10 & 11 & 11 & $\nearrow$ \\
\hline 3 Pedone 1.7 & 2477 & 8.0 & 1 & 48.00 & 48.00 & $0=$ & $==$ & & $=0$ & $1=$ & 01 & $=1$ & 11 & $\nearrow$ \\
\hline 4 Ethereal 8.67 & 2945 & 7.5 & 1 & 47.50 & 47.50 & $0=$ & $==$ & $=1$ & & $==$ & $0=$ & $1=$ & $=1$ & $\pi$ \\
\hline 5 ChessBrainVB 3.61 & 2981 & 7.5 & 1 & 43.50 & 43.50 & 00 & $==$ & $0=$ & $==$ & & $1=$ & 11 & $1=$ & $\nearrow$ \\
\hline 6 Toga II 4.01 & 2767 & 7.0 & 1 & 46.00 & 46.00 & $=0$ & 01 & 10 & $1=$ & $0=$ & & $=1$ & 10 & $\searrow$ \\
\hline 7 The Baron 3.41 & 2840 & 4.0 & 1 & 25.75 & 25.75 & $==$ & 00 & $=0$ & $0=$ & 00 & $=0$ & & $=1$ & $\searrow$ \\
\hline 8 Scorpio 2.79 & 2831 & 3.0 & 1 & 21.50 & 21.50 & $=0$ & 00 & 00 & $=0$ & $0=$ & 01 & $=0$ & & $\searrow$ \\
\hline
\end{tabular}

Fig. 4. The TCEC11 Division 4 cross-table: one DRR phase, 14 rounds, 56 games.

\section{Division 3: two DRR phases, 28 rounds, 112 games, tempo $30^{\prime}+10^{\prime \prime} / \mathrm{m}$}

\begin{tabular}{|c|c|c|c|c|c|c|c|c|c|}
\hline \multirow{2}{*}{ \# } & \multirow{2}{*}{ First four plies } & \multirow{2}{*}{ Rounds } & \multirow{2}{*}{\multicolumn{2}{|c|}{ ECO Opening }} & \multirow{2}{*}{ CHESS BASE ECO coding for the games } & \multicolumn{4}{|c|}{ TCEC11.D3 results } \\
\hline & & & & & & $1-0$ & $1 / 2-1 / 2$ & & nored \\
\hline 01 & 1. b3 e5 2. Bb2 Nc6 & $1 \& 08$ & A01 & Nimzovich-Larsen attack & $\mathrm{A} 01, \mathrm{~A} 01, \mathrm{~A} 01, \mathrm{~A} 01 ; \mathrm{A} 01, \mathrm{~A} 01, \mathrm{C} 50, \mathrm{~A} 01$ & 2 & 1 & 5 & 0 \\
\hline 02 & 1. Nf3 Nf6 2. g3 g6 & $02 \& 09$ & A05 & Reti, King's Indian attack & D02, D77, D78, A39; A15, D79 D73, D79 & 2 & 4 & 2 & 0 \\
\hline 03 & 1. e 4 c5 2. Nc3 Nc6 & $03 \& 10$ & $\mathrm{~B} 23$ & Sicilian, closed & $\mathrm{B} 23, \mathrm{~B} 45, \mathrm{~B} 33, \mathrm{~B} 23 ; \mathrm{B} 45, \mathrm{~B} 23, \mathrm{~B} 59, \mathrm{~B} 30$ & 1 & 6 & 1 & 0 \\
\hline 04 & 1. e4 c6 $2 . \mathrm{Nf} 3 \mathrm{~d} 5$ & $04 \& 11$ & $\mathrm{~B} 10$ & Caro-Kann defence & $\mathrm{B} 11, \mathrm{~B} 10, \mathrm{~B} 12, \mathrm{~B} 11 ; \mathrm{B} 15, \mathrm{~B} 10, \mathrm{~B} 11, \mathrm{~B} 15$ & 4 & 1 & 3 & 0 \\
\hline 05 & 1. Nf3 c5 2. c4 Nc6 & $05 \& 12$ & A04 & Reti opening & $\mathrm{A} 30, \mathrm{D} 30, \mathrm{~A} 35, \mathrm{~A} 30 ; \mathrm{D} 40, \mathrm{~A} 33, \mathrm{~A} 33, \mathrm{~A} 30$ & 3 & 3 & 1 & 1 \\
\hline 06 & 1. $\mathrm{d} 4 \mathrm{Nf6} 2 . \mathrm{Nf} 3 \mathrm{e} 6$ & $06 \& 13$ & A46 & Queen's pawn game & A46, D38, D38, D43; E11, D41, E52, D37 & 2 & 5 & 1 & 0 \\
\hline 07 & 1. e4 c5 2. c3 Nf6 & $07 \& 14$ & $\mathrm{~B} 22$ & Sicilian, Alapin's variation & $\mathrm{B} 22, \mathrm{~B} 22, \mathrm{~B} 22, \mathrm{~B} 22 ; \mathrm{B} 22, \mathrm{~B} 22, \mathrm{~B} 22, \mathrm{~B} 22$ & 0 & 8 & 0 & 0 \\
\hline 08* & 1. $\mathrm{d} 4 \mathrm{Nf6} 2 . \mathrm{c} 4 \mathrm{e} 6$ & $15 \& 22$ & E00 & Queen's pawn game & E56, E48, D35, D30; D59, D38, E39, E10 & 4 & 3 & 1 & 0 \\
\hline 09 & 1. c4 Nf6 2. Nc3 e6 & $16 \& 23$ & A17 & English Opening & $\mathrm{A} 18, \mathrm{~A} 18, \mathrm{~A} 18, \mathrm{E} 11 ; \mathrm{A} 18, \mathrm{~A} 34, \mathrm{~B} 44, \mathrm{D} 55$ & 3 & 5 & 0 & 0 \\
\hline $10 *$ & 1. e 4 c5 2. Nf3 Nc6 & $17 \& 24$ & B30 & Sicilian defence & $\mathrm{B} 30, \mathrm{~B} 31, \mathrm{~B} 31, \mathrm{~B} 54 ; \mathrm{B} 30, \mathrm{~B} 30, \mathrm{~B} 30, \mathrm{~B} 30$ & 1 & 4 & 3 & 0 \\
\hline 11 & 1. $\mathrm{d} 4 \mathrm{~d} 52 . \mathrm{Nf} 3 \mathrm{c} 6$ & $18 \& 25$ & D02 & Queen's pawn game & $\mathrm{D} 02, \mathrm{D} 02, \mathrm{D} 30, \mathrm{D} 02 ; \mathrm{D} 11, \mathrm{D} 02, \mathrm{D} 27, \mathrm{D} 12$ & 3 & 3 & 2 & 0 \\
\hline 12 & 1. e 4 e5 2. Nf3 Nf6 & $19 \& 26$ & $\mathrm{C} 42$ & Petrov's defence & $\mathrm{C} 42, \mathrm{C} 42, \mathrm{C} 42, \mathrm{C} 42 ; \mathrm{C} 42, \mathrm{C} 42, \mathrm{C} 42, \mathrm{C} 42$ & 1 & 6 & 1 & 0 \\
\hline 13 & 1. e4 d5 2. exd5 Qxd5 & $20 \& 27$ & B01 & Scandinavian defence & $\mathrm{C} 10, \mathrm{~B} 01, \mathrm{~B} 01, \mathrm{~B} 01 ; \mathrm{B} 01, \mathrm{~B} 01, \mathrm{~B} 01, \mathrm{~B} 01$ & 4 & 4 & 0 & 0 \\
\hline 14 & 1. $\mathrm{d} 4 \mathrm{~d} 62 . \mathrm{e} 4 \mathrm{~g} 6$ & $21 \& 28$ & A41 & Queen's pawn game & $\mathrm{B} 08, \mathrm{~A} 43, \mathrm{~A} 41, \mathrm{~B} 08 ; \mathrm{B} 08, \mathrm{~B} 08, \mathrm{~B} 08, \mathrm{~A} 43$ & 0 & 8 & 0 & 0 \\
\hline
\end{tabular}

Fig. 5. The 14 two-move openings chosen for Division 3 and CHESSBASE's ECO classification of the resulting games. 
Fourteen of the most frequent 100 two-move openings in CATOBASE were allocated to rounds 1-7 and 15-21, with colours reversed in rounds 8-14 and 22-28 as in Fig. 5. Two openings, asterisked, were used in Division 4.

\begin{tabular}{|c|c|c|c|c|c|c|c|c|c|c|c|c|c|c|}
\hline \# Engine & Rtng & Pts & DRR & SB & nSB & Fritz & Laser & Nemrno & Pedone & D'chess & Senpai & Ch'Brain & Ethrl & Move \\
\hline 1 Fritz 16 & 3151 & 18.5 & 2 & 238.25 & 59.56 & & $====$ & $===0$ & $==11$ & $====$ & $=11=$ & 1111 & $11==$ & $\pi$ \\
\hline 2 Laser 1.5 & 2562 & 17.5 & 2 & 228.25 & 57.06 & $====$ & & $10==$ & $====$ & $011=$ & $11=0$ & $=1=1$ & $111=$ & $\nearrow$ \\
\hline 3 Nemorino 4.01 & 2977 & 14.5 & 2 & 203.50 & 50.88 & $===1$ & $01==$ & & $10=0$ & $====$ & $===1$ & $====$ & $=01=$ & $\rightarrow$ \\
\hline 4 Pedone 1.7 & 2477 & 14.0 & 2 & 194.00 & 48.50 & $==00$ & $====$ & $01=1$ & & $111=$ & $0=10$ & $=0==$ & $====$ & $\rightarrow$ \\
\hline 5 Defenchess 271217 & 3076 & 14.0 & 2 & 188.50 & 47.13 & $====$ & $100=$ & $====$ & $000=$ & & $011=$ & 1110 & $==1=$ & $\rightarrow$ \\
\hline 6 Senpai 2.0 & 2881 & 12.5 & 2 & 169.50 & 42.38 & $=00=$ & $00=1$ & $===0$ & $1=01$ & $100=$ & & $====$ & $=110$ & $\rightarrow$ \\
\hline 7 ChessBrainVB 3.61 & 2981 & 11.0 & 2 & 145.50 & 36.38 & 0000 & $=0=0$ & $====$ & $=1==$ & 0001 & $====$ & & $101=$ & $\searrow$ \\
\hline 8 Ethereal 8.77 & 2945 & 10.0 & 2 & 140.50 & 35.13 & $00==$ & $000=$ & $=10=$ & $====$ & $==0=$ & $=001$ & $010=$ & & $y$ \\
\hline
\end{tabular}

Fig. 6. The TCEC11 Division 3 cross-table: two DRR phases, 28 rounds, 112 games.

Here we had a $45.5 \%$ win-rate, $27.7 \% 1-0$ and $17.8 \%$ 0-1. The longest win (1-0) was ETHEREALNEMORINO g51 at $149 \mathrm{~m}$ and the longest draw, SENPAI-PEDONE g52 at $201 \mathrm{~m}$. TCEC newcomers DEFENCHESS, PEDONE and SENPAI successfully remained in Division 3 after their promotion. LASER 1.5 was underrated at 2562 .

\section{Division 2: two DRR phases, 28 rounds, 112 games, tempo $45^{\prime}+10^{\prime \prime} / \mathrm{m}$}

\begin{tabular}{|c|c|c|c|c|c|c|c|c|c|}
\hline \multirow[t]{2}{*}{ \# } & \multirow{2}{*}{ First four plies } & \multirow{2}{*}{ Rounds } & \multirow{2}{*}{ ECO } & \multirow{2}{*}{ Opening } & \multirow{2}{*}{ CHESS BASE ECO coding for the games } & \multicolumn{4}{|c|}{ TCEC11.D2 results } \\
\hline & & & & & & & & & \\
\hline 01 & 1. $\mathrm{d} 4 \mathrm{Nf6} 2 . \mathrm{Nc} 3 \mathrm{~d} 5$ & $01 \& 08$ & A45 & Queen's Pawn game & D00, D00, D00, D03; B13, D00, D00, D01 & 2 & 2 & 3 & 1 \\
\hline 02 & 1. c4 e5 2. Nc3 Nc6 & $02 \& 09$ & A 25 & English, Sicilian reversed & $\mathrm{C} 01, \mathrm{C} 01, \mathrm{~A} 28, \mathrm{~A} 25 ; \mathrm{A} 28, \mathrm{~A} 26, \mathrm{~A} 28, \mathrm{~A} 25$ & 3 & 3 & 2 & 0 \\
\hline 03 & 1. e4 c5 2. Nc3 d6 & $03 \& 10$ & $\mathrm{~B} 23$ & Sicilian Defence, closed & В30, В23, B50, В50; В23, В50, В23, В56 & 3 & 4 & 1 & 0 \\
\hline 04 & 1. d4 Nf6 2. Bf4 d5 & $04 \& 11$ & A45 & Queen's Pawn game & B13, B13, D00, D02; B13, D00, D02, D00 & 6 & 0 & 2 & 0 \\
\hline $\mathbf{0 5} *$ & 1. e4 e6 $2 . \mathrm{d} 4 \mathrm{~d} 5$ & $05 \& 12$ & $\mathrm{C} 00$ & French Defence & $\mathrm{C} 01, \mathrm{C} 06, \mathrm{C} 01, \mathrm{C} 06 ; \mathrm{C} 01, \mathrm{C} 13, \mathrm{C} 08, \mathrm{C} 08$ & 1 & 5 & 2 & 0 \\
\hline 06 & 1. e4 c5 2. Nf3 e6 & $06 \& 13$ & B40 & Sicilian Defence & B45, B22, B45, B40; B45, B30, B40, B22 & 2 & 4 & 2 & 0 \\
\hline 07 & 1. Nf3 d5 2. c4 c6 & $07 \& 14$ & A09 & Reti opening & D12, D27, D47, D12; D46, D45, D12, A11 & 2 & 5 & 1 & 0 \\
\hline 08 & 1. $\mathrm{d} 4 \mathrm{~d} 52 . \mathrm{c} 4 \mathrm{dxc} 4$ & $15 \& 22$ & D20 & Queen' Gambit Accepted & D25, D20, D26, D25; D11, D27, D27, D20 & 3 & 4 & 1 & 0 \\
\hline 09* & 1. e4 c6 $2 . \mathrm{d} 4 \mathrm{~d} 5$ & $16 \& 23$ & B12 & Caro-Kann Defence & $\mathrm{B} 12, \mathrm{~B} 15, \mathrm{~B} 12, \mathrm{~B} 12 ; \mathrm{B} 15, \mathrm{~B} 12, \mathrm{~B} 15, \mathrm{~B} 15$ & 2 & 6 & 0 & 0 \\
\hline 10 & 1. Nf3 Nf6 2. 4 g6 & $17 \& 24$ & A15 & English opening & D98, E60, D85, E91; B36, D85, D92, E90 & 4 & 4 & 0 & 0 \\
\hline 11 & 1. d4 Nf6 2. c4 c6 & $18 \& 25$ & A50 & Queen's Pawn game & D10, D30, D30, D30; D13, D27, D12, D45 & 5 & 3 & 0 & 0 \\
\hline 12 & 1. e4 c5 2. c3 d5 & $19 \& 26$ & $\mathrm{~B} 22$ & Sicilian: Alapin's variation & В22, В22, В22, В22; В22, В22, В22, В22 & 2 & 6 & 0 & 0 \\
\hline 13 & 1. e4 e5 2. Nf3 d6 & $20 \& 27$ & $\mathrm{C} 41$ & Philidor's Defence & $\mathrm{C} 41, \mathrm{C} 41, \mathrm{C} 41, \mathrm{C} 41 ; \mathrm{C} 41, \mathrm{C} 41, \mathrm{C} 46, \mathrm{~B} 50$ & 3 & 4 & 1 & 0 \\
\hline 14 & 1. e4 d6 2. d4 Nf6 & $21 \& 28$ & B07 & Pirc Defence & А 43, В07, В08, В07; В08, В00, В07, В07 & 1 & 6 & 1 & 0 \\
\hline
\end{tabular}

Fig. 7. The 14 two-move openings chosen for Division 2 and CHESSBASE's ECO classification of the resulting games.

\begin{tabular}{|c|c|c|c|c|c|c|c|c|c|c|c|c|c|c|}
\hline \# Engine & Rtng & Pts & DRR & SB & nSB & Jonny & Laser & Texel & Arasan & Fritz & Vajolet & Bobcat & Wasp & Move \\
\hline 1 Jonny 8.1 & 3215 & 20.0 & 2 & 255.75 & 63.94 & & $====$ & $1===$ & $1==1$ & $11=1$ & $=11=$ & $==1=$ & $111=$ & $\pi$ \\
\hline 2 Laser 1.5 & 2562 & 17.5 & 2 & 226.00 & 56.50 & $====$ & & $====$ & $1===$ & $====$ & $=1=1$ & 1101 & $11==$ & $\lambda$ \\
\hline 3 Texel $1.08 \mathrm{a} 8$ & 3159 & 16.5 & 2 & 210.50 & 52.63 & $0===$ & $====$ & & 1010 & $11==$ & $====$ & $11=0$ & $11=1$ & $\rightarrow$ \\
\hline 4 Arasan 20.4.1 & 3120 & 14.0 & 2 & 182.25 & 45.56 & $0==0$ & $0===$ & 0101 & & $1==0$ & $==10$ & $1=11$ & $=1=0$ & $\rightarrow$ \\
\hline 5 Fritz 16 & 3151 & 14.0 & 2 & 170.00 & 42.50 & $00=0$ & $====$ & $00==$ & $0==1$ & & $10==$ & 1101 & $111=$ & $\rightarrow$ \\
\hline 6 Vajolet2 2.5 & 3064 & 13.0 & 2 & 170.50 & 42.63 & $=00=$ & $=0=0$ & $====$ & $==01$ & $01==$ & & $=1=1$ & $====$ & $\rightarrow$ \\
\hline 7 Bobcat 8 & 3129 & 10.0 & 2 & 130.75 & 32.69 & $==0=$ & 0010 & $00=1$ & $0=00$ & 0010 & $=0=0$ & & $11=1$ & $\searrow$ \\
\hline 8 Wasp TCEC S11 & 3094 & 7.0 & 2 & 101.75 & 25.44 & $000=$ & $00==$ & $00=0$ & $=0=1$ & $000=$ & $====$ & $00=0$ & & $\searrow$ \\
\hline
\end{tabular}

Fig. 8. The TCEC11 Division 2 cross-table: two DRR phases, 28 rounds, 112 games.

Fourteen of the most frequent 100 two-move openings in CATOBASE were allocated to rounds 1-7 and 15-28 with colours reversed in rounds 8-14 and 22-28 as in Fig. 7. Two asterisked openings were used in Division 4. This division provided a 50.0\% win-rate, 35.7\% 1-0 and 14.3\% 0-1. JONNY was the undefeated and clear winner and LASER, with only one loss, took second over TEXEL. 


\section{Division 1: four DRR phases, 56 rounds, 224 games, tempo $60^{\prime}+10^{\prime \prime} / \mathrm{m}$}

The games of the first DRR were played without opening books from the initial position. For the remaining 168 games, a TCEC fan, Nikolaos Konstantakis, chose 84 openings according to Nelson Hernandez' (2018) guidelines. Most openings mandated five moves, the remainder being six- and seven-movers.

\begin{tabular}{|c|c|c|c|c|c|c|c|c|c|c|c|c|c|}
\hline Engine & Rtng & Pts & SB & nSB & And & Fizbo & Booot & Jonny & Gull & Laser & Hannibal & Nirvana & Move \\
\hline Booot 6.2 & 1 & 31.0 & 838.50 & 52.41 & $=====0=$ & $0=110$ & & $==0=$ & $===$ & $====111=$ & $==0$ & $==1=====$ & $\rightarrow$ \\
\hline Gull 3 & 3217 & 26.5 & 726.50 & 45.41 & $==00=0==$ & $====$ & $0==0====$ & $1==1$ & & $===$ & $1=1$ & $=1=====0$ & $\rightarrow$ \\
\hline Laser 1.5 & 3201 & 24.5 & 639.75 & 39.98 & $00=0=00=$ & $=010=000$ & $====000=$ & $=100==0=$ & $0=======$ & & $==11=11=$ & $=1=$ & $\rightarrow$ \\
\hline al 121017 & 3203 & 23.0 & 653.75 & 40.86 & $===0$ & $==0=01==$ & $==10===0$ & $=0=0===$ & $10=0$ & $=00=00=$ & & $=01=1===$ & 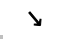 \\
\hline
\end{tabular}

Fig. 9. The TCEC11 Division 1 cross-table: four DRR phases, 56 rounds, 224 games.

Given the ELO range of 107, the winrate was 37.1\%, 26.8\% 1-0 and 10.3\% 0-1. Following promotions from Divisions 3 and 2, the clearly under-rated LASER 1.5 had its ELO uplifted by 639 to 3201. It just survived in Division 1, taking half its points from the demoted HANNIBAL and NIRVANA. Also just promoted, JONNY continued to acquit itself well in mid-table. ANDSCACS ran out a clear winner of this division. Perhaps the most notable wins 'below the diagonal' were LASER-FIZBO g59, HANNIBALBOOOT g74, NIRVANA-JONNY g77 and HANNIBAL-FIZBO g146.

\section{Division P: six DRR phases, 84 rounds, 336 games, tempo 90' $+10^{\prime \prime} / \mathrm{m}$}

There is always speculation as to whether engine authors will update their engines before their next appearance, particularly with regard to Robert Houdart and HOUDINI, the current TCEC champion. Robert in fact advised TCEC that there was a popular misconception among TCEC fans that an updated version of HOUDINI existed!

In the Premier Division, the games of the first DRR were also played without opening books from the initial position. The second author chose 4-move openings for the remaining games. Given the ELO range of 195, this produced a 39.0\% win rate, 29.2\% 1-0 and 9.8\% 0-1 with just $6.9 \%$ of the wins being below the diagonal of the final x-table of Fig. 10. First-player advantage, ELO rating and consistent form were starting to show a clearer advantage.

The longest win was FIZBO-FIRE g314's 1-0 at 217m, and the longest draw HOUDINI-STOCKFISH, g260 at $198 \mathrm{~m}$. GINKGO-FIRE, g171, was a good argument for 6m-EGT adjudication, theoretically drawn at 6-man KRPkbp position 54b and only ending with position 148w.

KOMODO-STOCKFISH, g28, 1-0 was a notable 'underdog win and STOCKFISH's sole loss. ANDSCACSKOMODO, g210, was another, finishing in KRPPPkrpp, a 1-0 win which FINALGEN (Romero, 2018) is able to confirm. The decisive games between the top three were g28 (as above), g58, g170, g224, g232 and the final $\mathrm{g} 336$.

The chat site Twitch (2018) and Wool (2018) provided observations across TCEC11 and 'GM Thechesspuzzler' (2018) dedicated a comprehensive Youtube playlist to this division and was perhaps the most frequent commentator, covering the following games: 
With the exception of STOCKFISH, which outperformed its TCEC ELO, the engines here ranked in ELO order. The top three, just 9 ELO apart, were rated 100 ELO better than the others so the eventual podium was no surprise. KOMODO took third place on 51.5 points, losing its head-to-head matches with HOUDINI and STOCKFISH while the latter was notably more successful than in TCEC10 in winning against lesser opposition. The one decisive result between STOCKFISH and HOUDINI suggested a close Superfinal.

\begin{tabular}{|c|c|c|c|c|c|c|c|c|c|c|c|c|}
\hline Engine & Rtng & Pts & nSB & Stockfish & Houdini & Komodo & Fire & Chiron & Andscacs & Fizbo & Ginkgo & Move \\
\hline Stockfish 100218 & 3456 & 61.0 & 63.69 & & $=======1==$ & $0======1===1$ & $1=1==-1=1=1=$ & $==11===1111=$ & $11=1=1=1=1=1$ & $111=1111111=$ & $=111=11=11=1$ & $\pi$ \\
\hline Houdini 6.03 & 3461 & 54.5 & 58.70 & $=======0===$ & & $==1===1=1===$ & $==1==1===1==$ & $====1=111===$ & $1=====1=1=11$ & $=1=1=1=1=1=1$ & $111=1=1=====$ & $\pi$ \\
\hline Komodo 2012.00 & 3454 & 51.5 & 54.85 & $1=====0==0$ & $=0===0=0==$ & & $======1==11$ & $=1==11==11==$ & $\mathrm{l}=\mathrm{l}=\mathrm{l}==0=111$ & $====1==111=1$ & $1===11==1==1$ & $\rightarrow$ \\
\hline Chiron 110218 & 3284 & 36.0 & 38.85 & $==00==0000=$ & $====0=000===$ & $=0=00=00=$ & $===0=0=0==0$ & & $=====0====1=$ & $1101=======1$ & $=11==1======$ & $\rightarrow$ \\
\hline Andscacs 0.93 & 3347 & 35.0 & 37.56 & $00=0=0=0=0=0$ & $0====0=0=00$ & $0=0=0==1=000$ & $======0====$ & $====1===0=$ & & $1==0=01=0=$ & $1=1=111====$ & $\rightarrow$ \\
\hline Fizbo 2 & 3273 & 31.0 & 32.82 & $000=0000000=$ & $=0=0=0=0=0=0$ & $===0=0000=0$ & $0=0==0=0==1$ & $0010======0$ & $0==1==10==1=$ & & $=1=1=1=10=1=$ & $\downarrow$ \\
\hline
\end{tabular}

Fig. 10. The Premier Division cross-table: six DRR phases, 84 rounds, 336 games.

To judge from the normalised Sonneborn-Berger scores, the winning engines, in decreasing order of dominance in the context of their initial division, were DEFENCHESS (D4, 66.25), JONNY (D2, 63.94), STOCKFISH (DP, 63.69), ANDSACS (D1, 60.55) and FRITZ (D3, 59.56).

\section{The TCEC11 Superfinal match: 100 games, tempo $120^{\prime}+15^{\prime \prime} / \mathrm{m}$}

And so the stage was set for a two-week Superfinal: STOCKFISH versus HOUDINI, the TCEC Grand Champion of Seasons 6 and 9 versus the TCEC Grand Champion after the last Season and after Seasons 1,2 and 4. Given the results of the Premier Division (though scarcely conclusive between the two contestants themselves) the news of a STOCKFISH update and the news of no HoUDINI update, prior polling not surprisingly had STOCKFISH as favourite. ELOs were reset at 3546 and 3489, the difference of 57 suggesting a benchmark 52-48 win for Stockfish with 78 draws, albeit with the incorrect assumption that games started from the initial position.

Each pair of games used a different one of fifty openings chosen by Jeroen Noonen: they ranged in length from 3 to 28 ply. Jeroen aimed for a win-rate of at least $20 \%$ with aspirations for the $25-26 \%$ of previous Superfinals. STOCKFISH played White in odd-numbered games and Black for the following game.

\begin{tabular}{llllllll}
\hline \multirow{2}{*}{ TCEC Superfinal } & \multirow{2}{*}{ ELO } & \multirow{2}{*}{ Decisive games } & \multicolumn{5}{c}{ Wins after $\boldsymbol{n}$ games } \\
& & & $\mathbf{2 0}$ & $\mathbf{4 0}$ & $\mathbf{6 0}$ & $\mathbf{8 0}$ & $\mathbf{1 0 0}$ \\
\hline \multirow{2}{*}{ Stockfish 260318} & \multirow{2}{*}{3546} & $05,07, \underline{12}, 21, \underline{24}, \underline{26}, 27,29, \underline{30}, 31$, & & & & & \\
& $35, \underline{42}, 43,61, \underline{66}, 75,79,81, \underline{96}, 99$ & $3-0$ & $11-1$ & $13-1$ & $17-2$ & $20-2$ \\
Houdini 6.03 & 3489 & $32, \overline{78}$ & & & & & \\
\hline
\end{tabular}

Fig.11. The Superfinal match of 100 games: the decisive games, Black wins underlined.

Across the 100 games, STOCKFISH scored $+20=78-2$, an ELO superiority of 63, comparable with its estimated ELO superiority of 57 which predicted four wins for HOUDINI. Given the 15 wins for White and 7 (all to STOCKFISH) for Black, White seems to have an ELO advantage of 28 over Black. The winrate of $22 \%$ fell neatly between Jeroen's minimum goal of $20 \%$ and his aspiration of $25-26 \%$. 
Given that openings were mandated but played out by the engines from both sides, the match is best thought of as 50 duals of two games each. STOCKFISH scored $+18=31-1$ in 'dual terms' as it won both games 29 and 30, shared White wins in games 31-32 with HOUDINI, but lost game 78.

The score is the only input to ELO calculations but does not reflect the closeness of the contest. Games were on average some 73.4 moves and 04:08:53 in length despite TCEC's draw rule pre-empting a 3xrepetition or 50-move-rule draw on 32 occasions. The longest game was the drawn g97 at $168 \mathrm{~m}$ and 5:23:04 while the longest win was $\mathrm{g} 42$ at $167 \mathrm{~m}$ and 5:21:04. There was one 50mr draw in game 45, and one stalemate finish, game 6 being ended abruptly by HOUDINI offering a Queen which Black's King could not refuse. Games 05, 07, 30, 31, 43, 96 and 99 were commentated on by GM_Thechesspuzzler (2018).

\section{$7 \quad$ On the openings and endgames}

Again, Nelson Hernandez and Jeroen Noonen are to be congratulated on the variety they introduced into the games through their choice of mandated openings, done without favouring any particular engine because of colour-symmetry. For divisions 4, 3 and 2, the ECO codes in the tables and supplied pgns (Haworth and Hernandez, 2018b) are provided by CHESSBASE and differ in some 20\% of cases from the contemporaneous classification given by TCEC which does not consider transpositions.

Surprisingly, some thirteen engines, including ANDSCACS and GINKGO in the Premier Division, did not consult endgame tables at all, while almost all others used the provided set of sub-7-man DTZ ${ }_{50}$ " EGTs created by Ronald de Man (2018). Despite this, all games reduced to five men were adjudicated by DTM EGTs ignoring the 50-move rule and regardless of whether both sides were using 6-man EGTs or not. Fortunately, no 50mr controversies arose but DTZ 50 " EGT adjudication now seems more pragmatic. Given the TCEC win rule and the fact that both engines were using 6-man EGTs, the 43 superfinal games reaching 7-man endgames were, perhaps predictably, all drawn in theory at the 7-man point as they were in practice. The 22 superfinal wins were agreed with 8-18 men on the board.

The runtime statistics revealed further endgame surprises, for at least the first author. Engines often consulted the EGTs really early in the game, and did not necessarily settle for the theoretical result in 6-man positions, instead looking for the 'best' winning or drawing move. With the EGTs on SSD, millions of references to them were often made for just one move, STOCKFISH clocking over one billion such calls at 10-man position 44w of game 47 at a rate of over 1,630,000 positions/sec.

\section{Summary and reflection}

The list of engines participating in TCEC Season 11 is a testament to the level of activity in the chess programming community and to its international scope. Both are promoted by the whole sequence of events (TCEC, 2018). Contrary to popular belief, computer chess did not stop when IBM's DEEP BLUE edged the second match against Garry Kasparov. It is worth remembering that Garry is still 4-3 up on wins against DEEP BLUE across the two matches. These are now worth revisiting in the context of his mature, frequently reviewed and well received reflection on the subjects of artificial intelligence and 'man and machine' (Kasparov, 2017).

All participating authors are to be congratulated on their achievements and on the many fine TCEC11 games that resulted. It would be interesting to have the first-hand, individual perspectives of some of these authors on the record. All podium placers should be particularly delighted with their results, 
especially if they were promoted and, like ANDSCACS, DEFENCHESS, FRITZ, JONNY, LASER, PEDONE and SENPAI, emerged from TCEC11 in a higher division. LASER alone achieved a double promotion, thanks to some urgent development work which also removed bugs revealed to the author during the previous TCEC10 season.

Particular congratulations go to the 'big three' - HOUDINI, KOMODO and STOCKFISH - who remain on the top step. This time, STOCKFISH recovered from its relative failure in TCEC10 to recover the title of TCEC Grand Champion. This is certainly a win which its community of contributing testers and supporters, particularly the leading authors, will and should enjoy. STOCKFISH was also Grand Champion after TCEC Seasons 6 and 9.

The divisional structure of TCEC11 clearly works to advantage and is retained for TCEC12. Complete pgn files, with some decisive games played out to greater clarity, plus detailed results of and runtime data on all the games has been made available (Haworth and Hernandez, 2018b) to facilitate later and more detailed study. TCEC11 is a comprehensive snapshot of the status of computer chess today and will repay that further examination.

\section{REFERENCES}

Ballicora, M. A. (2018). https://tinyurl.com/gav-egt1. Gaviota 'DTM' Depth to Mate endgame tables. de Man, R. (2018). http://tablebase.sesse.net/syzygy/. Site providing 5- and 6-man DTZ50" EGTs.

'GM Thechesspuzzler' (2018). https://tinyurl.com/GMtcp-pl. TCEC video playlists.

Haworth, G. MC. (2014). Chess Endgame News. ICGA Journal, 37(2), pp. 117-119.

Haworth, G. $\mathrm{M}^{\mathrm{c}} \mathrm{C}$. and Hernandez, N. (2018a). TCEC10: the $10^{\text {th }}$ Top Chess Engine Championship. ICGA Journal 40(2), pp. 113-118. doi: 10.3233/ICG-180045. http://centaur.reading.ac.uk/75887/ for supporting data - results, statistics and pgn files.

Haworth, G. $M^{\mathrm{c}} \mathrm{C}$. and Hernandez, N. (2018b). http://centaur.reading.ac.uk/75899/. TCEC11: the 11 Top Chess Engine Championship. This article plus supporting data - results, statistics and pgn files.

Hernandez, N. (2018). Choosing Chess Openings for TCEC10. ICGA Journal, 40(3), pp. 213-215. Doi: 10.3233/ICG-190082.

Intel (2017). https://tinyurl.com/icga042. Intel's specification of the Xeon ${ }^{\circledR}$ E5-2699V4 processor.

Kasparov, G. (2017). Deep Thinking. John Murray. ISBN 978-1473653504.

Nalimov, E.V., Haworth, G.McC. and Heinz, E.A. (2000). Space-Efficient Indexing of Endgame Tables. ICGA Journal, 23(3), pp. 148-162. ISSN 1389-6911.

Romero, P. P. (2018). http://finalgenchess.ovh/home_ing.php. FINALGEN download and tutorial.

Shawul, D. (2018). https://github.com/dshawul/egbbdll. Probing code for Scorpio bitbases.

TCEC (2018). http://tcec.chessdom.com/archive.php. Current and past TCEC tournaments.

Twitch (2018). https://www.twitch.tv/. A video/chat platform and community for gamers.

Wool, A. (2018). http://mytcecexperience.blogspot.co.uk/ TCEC blog. 